\title{
Effects of swimming on pain and inflammatory factors in rats with lumbar disc herniation
}

\author{
YIZHUAN HUANG ${ }^{1}$, ZHENDONG ZHONG $^{2}$, DANDAN YANG $^{3}$, LINGYUAN HUANG $^{3}$, FENGJAO HU $^{3}$, \\ DAN LUO $^{3}$, LINXIA YAN ${ }^{3}$, RONG WANG ${ }^{3}$, LIJIE ZHANG ${ }^{3}$, XUEMEI HU ${ }^{3}$ and JINLI HE ${ }^{3}$ \\ ${ }^{1}$ Department of Spinal Specialty, The Affiliated Sports Hospital of Chengdu Sport Institute, Chengdu, Sichuan 610041; \\ ${ }^{2}$ Institute of Laboratory Animals of Sichuan Academy of Medical Science, Sichuan Provincial People's Hospital, \\ Chengdu, Sichuan 610072; ${ }^{3}$ Chengdu Lilai Biotechnology Co., Ltd., Chengdu, Sichuan 610000, P.R. China
}

Received July 5, 2018; Accepted July 8, 2019

DOI: $10.3892 / e t m .2019 .7893$

\begin{abstract}
The aim of the present study was to identify the effect of swimming on nerve root pain in rats with lumbar disc herniation (LDH). A total of 72 male Sprague Dawley rats $(215 \pm 15 \mathrm{~g})$ were randomly divided into three groups ( $n=24 /$ group): The sham operation, model and exercise intervention groups, with the latter undergoing 4 weeks of swimming training. On days $0,7,14$ and 28 following surgery, the changes in the post-limb mechanical claw threshold, the phospholipase A2 (PLA2), interleukin (IL)-6 and tumor necrosis factor (TNF)- $\alpha$ mRNA expression levels, the secretory PLA2 (sPLA2) expression, the IL- 6 and TNF- $\alpha$ content, the nuclear factor (NF)- $\mathrm{kBp} 65$ protein expression level in the nucleus pulposus, and the apoptotic rate of the nucleus pulposus cells were detected. The results demonstrated that, in the model group, the threshold of hind paw withdrawal was decreased, and that the sPLA2 expression, IL- 6 and TNF- $\alpha$ content, PLA2, IL- 6 and TNF- $\alpha$ mRNA and NF- $\mathrm{kBp} 65$ protein expression levels in the nucleus pulposus were increased. The apoptotic rate of the nucleus pulposus cells was increased from day 7 following surgery, as compared with the sham operation group. In the exercise intervention group, the hind paw withdrawal threshold increased and the TNF- $\alpha$ and IL- 6 content, sPLA2 expression and PLA2, IL-6 and TNF- $\alpha$ mRNA and NF- $\kappa$ Bp 65 protein expression levels were decreased from day 14 following surgery, and the apoptotic nucleus pulposus cells were decreased from day 7 following surgery, as compared with the model group. Collectively, the present data suggest that swimming can significantly reduce nerve root pain and inhibit inflammatory reaction in $\mathrm{LDH}$, which can have positive effects on the treatment of LDH.
\end{abstract}

Correspondence to: Mr. Yizhuan Huang, Department of Spinal Specialty, The Affiliated Sports Hospital of Chengdu Sport Institute, 251 Wuhou Temple Street, Chengdu, Sichuan 610041, P.R. China E-mail: hyzbiology@yeah.net

Key words: lumbar disc herniation, swimming exercise, phospholipase A2, tumor necrosis factor- $\alpha$, interleukin- 6 , rats

\section{Introduction}

Back pain is one of the most common diseases in modern society, with $60-80 \%$ of people experiencing it at least once in their lifetime (1). Lumbar disc herniation (LDH) is the most common back pain disorder in clinical practice, with a morbidity of $20-30 \%$ according to previous reports (2-4). In recent years, with the continuous development of society and the change of working and living habits, LDH is affecting an increasing number of young patients (5). The highest prevalence of LDH is among adults aged $30-50$ years, with a male to female ratio of 2:1 (6). LDH is defined as a recurrent symptom of lower back pain and sciatica whose pathophysiology includes mechanical compression, autoimmunity and chemical inflammation of the nerve roots $(7,8)$. However, the exact causes of lower back pain and sciatica are not fully understood and as such, there is no effective treatment for primary symptoms.

The treatment of symptomatic LDH includes non-invasive therapy, minimally invasive procedures and surgery (9). It has been demonstrated that surgical and non-surgical treatment effectively treats symptomatic LDH (10). However, the incidence of operation-associated complications is $15-30 \%$ and the recurrence rate after operation is $2-25 \%(11,12)$. Thus, non-surgical treatment remains the first choice for most patients. Physical therapy serves an important role in the management of LDH and is often recommended for the treatment of pain and for the restoration of functional and neurological deficits (13). Active exercise therapy is a form of physical therapy that is more popular than passive therapy and includes activities such as walking, cycling or yoga (14). However, to the best of our knowledge, no studies have explored the possible role of swimming in LDH.

Combined with the pathophysiological characteristics of LDH, the present study constructed an animal model of LDH to determine the expression of phospholipase A2 (PLA2), interleukin (IL)-6, tumor necrosis factor- $\alpha$ (TNF- $\alpha$ ) and NF- $\mathrm{kBp} 65$, and the apoptosis of nucleus pulposus cells following swimming therapy. The present study may provide a theoretical basis for LDH exercise treatment and may also determine the optimal forms of exercise that can be applied for therapy. 


\section{Materials and methods}

Animals. A total of 72 male Sprague Dawley rats (weight, $215 \pm 15 \mathrm{~g}$; age, 8 weeks) were purchased from the Animal Center of the West China Medical College of Sichuan University (Chengdu, China). All animals were housed in the animal laboratory under controlled, conventional conditions (temperature, $24 \pm 1^{\circ} \mathrm{C}$; humidity, $60 \pm 10 \%$; 12-h light-dark cycle), and were given free access to food and water during the experimental session. Following a week of adaptation, rats were randomly divided into three groups ( $n=24 /$ group): The sham operation, model and exercise intervention groups. The experimental protocol for the care and use of laboratory animals was approved by the Experimental Animal Ethics Committee of West China Hospital of Sichuan University (Chengdu, China). The associated permit number is $2018 / 66 \mathrm{~A}$.

Establishment of rat LDH model. The lumbar disc herniation model was established in the rats as previously reported $(15,16)$. All rats were anesthetized by an intraperitoneal injection of $10 \%$ chloral hydrate $(350 \mathrm{mg}$ chloral hydrate/kg rat body weight; Animal Center of the West China Medical College of Sichuan University). The hair on the rats' abdomen and lower back was clipped. The left side of the body was incised and routine disinfection was performed to avoid wound infection. The incision was 3-3.5 cm long. The nucleus pulposus (NP) was harvested between the 2 nd and 3rd coccygeal intervertebral disc of rat tails. In the model and exercise intervention groups, the L5 and L6 nerve roots were cut after exposing the ventral posterior wall. Harvested NP was then placed on the top of the left L5 and L6 nerve roots. Next, the wound was washed with saline and bandaged with sterile gauze. In the sham group, the intervertebral disc was snipped without NP transplantation. Rats were separately fed in a single cage and fasted for solids and liquids following surgery. Animals were administered with penicillin for 3 successive days. The rats had normal appetite without obvious infection signs, peritonitis or death following administration of $10 \%$ chloral hydrate.

Exercise intervention. Rats in the exercise intervention group were treated on day 5 post-surgery. The rats were placed in a pool sized 100x70x60 $\mathrm{cm}$ with a water depth of $50 \mathrm{~cm}$. The water temperature was set to $30 \pm 2^{\circ} \mathrm{C}$. Initially, the animals were subjected to exercise twice for $10 \mathrm{~min}$. Next, animals trained for 20,30 and $45 \mathrm{~min}$ on days 1, 2 and 3, respectively. The training occupied $60 \mathrm{~min}$ a day, 6 days a week for 4 weeks.

Detection of the hind paw withdrawal threshold in LDH rats. The hind paw withdrawal threshold was detected as previously described $(17,18)$. Rats were placed in the test box of a heat pain checker (PL-200) with thermal light exposure. The thermal light was focused on the back half of one side of the rat foot through the bottom glass plate, and the spot diameter was $5 \mathrm{~mm}$. The time from exposure to withdrawal was recorded. The interval between tests lasted for a minimum of $5 \mathrm{~min}$, and the mean value was measured three times.
Material and specimen handling. Rats were sacrificed via cervical dislocation following anesthesia by intraperitoneal injection of $10 \%$ chloral hydrate $(350 \mathrm{mg}$ chloral hydrate $/ \mathrm{kg}$ rat body weight) at 7, 14 and 28 days following exercise intervention. After being soaked in $70 \%$ ethanol for $5 \mathrm{~min}$, the skin of rats was cut along the posterior median line, paravertebral muscle was separated and the lumbar vertebral segment was removed. Then, intervertebral disc fiber ring was cut open with a sharp knife under microscopy, and the NP tissue was removed, fixed with $4 \%$ paraformaldehyde at $4^{\circ} \mathrm{C}$ for $48-72 \mathrm{~h}$, and the remaining NP tissues were preserved at $-80^{\circ} \mathrm{C}$.

Reverse transcription quantitative polymerase chain reaction $(R T-q P C R)$. The relative expression of PLA2, TNF- $\alpha$, IL- 6 and $\beta$-actin were evaluated by RT-qPCR. Total RNA was extracted from NP tissue using TRIzol reagent (Thermo Fisher Scientific, Inc.) and cDNA was synthesized using PrimeScript $^{\mathrm{TM}}$ RT reagent kit (Takara Biotechnology Co., Ltd.) at $37^{\circ} \mathrm{C}$ for $15 \mathrm{~min}$ and $85^{\circ} \mathrm{C}$ for $5 \mathrm{sec}$, in accordance with the manufacturer's protocol. The expression levels of PLA2, TNF- $\alpha$, IL- 6 and $\beta$-actin were then detected with SYBR Premix Ex Taq II (Takara Biotechnology Co., Ltd). The thermocycling conditions were as follows: $3 \mathrm{~min}$ at $95^{\circ} \mathrm{C}$; 40 cycles of $95^{\circ} \mathrm{C}$ for $5 \mathrm{sec}$ and $60^{\circ} \mathrm{C}$ for $30 \mathrm{sec}$; followed by $72^{\circ} \mathrm{C}$ for $30 \mathrm{sec}$. The data was analyzed using Bio-Rad CFX Manager software (version 3.0; Bio-Rad Laboratories, Inc.). The $2^{-\Delta \Delta C q}$ method was used for comparative quantitation (19). $\beta$-actin was used as endogenous controls. Primer sequences are presented in Table I.

Terminal deoxynucleotidyl-transferase-mediated dUTP nick end labeling (TUNEL) staining. NP tissues were fixed with $4 \%$ paraformaldehyde for $48-72 \mathrm{~h}$ at room temperature. NP was then embedded in paraffin and 5- $\mu \mathrm{m}$-thick paraffin sections were prepared. Apoptotic cells were detected using an in situ cell death detection kit (Roche Applied Science) at $37^{\circ} \mathrm{C}$ for $1 \mathrm{~h}$ in the dark, in accordance with the manufacturers protocol. Samples were then rinsed in $0.1 \mathrm{M}$ PBS three times for $5 \mathrm{~min}$, incubated in Converter peroxidase (POD) for $30 \mathrm{~min}$ at $37^{\circ} \mathrm{C}$, rinsed in $0.1 \mathrm{M}$ PBS three times for $5 \mathrm{~min}$ and color-developed with 3,3'-diaminobenzidine for $5 \mathrm{~min}$ at room temperature. Samples were subsequently counterstained with hematoxylin at room temperature for 1-3 sec. Following complete washing with distilled water, sections were mounted with Rhamsan gum (Beijing Solarbio Science \& Technology Co., Ltd.) and observed under a fluorescence microscope (Olympus Corporation; magnification, $\mathrm{x} 400$ ). Apoptotic cells exhibited brown staining within the nucleus.

Annexin-V/propidium iodide (PI) double-staining assay. The collected NP cells were resuspended in $100 \mu 1$ Annexin V binding buffer ( $1 \times 10^{5}$ cells) with $5 \mu$ l Annexin V-fluorescein isothiocyanate and $5 \mu \mathrm{lPI}$ (cat. no. 556547; BD Biosciences). Subsequently, cell apoptosis was detected using a FACSCalibur ${ }^{\mathrm{TM}}$ flow cytometer (BD Biosciences) within $1 \mathrm{~h}$. Data were analyzed using FlowJo 10.07 software (Tree star, Inc.).

Detection of secretory (s)PLA2 activity and TNF- $\alpha$ and IL-6 contents. NP tissue $(100 \mathrm{mg})$ was rinsed with $1 \mathrm{xPBS}$, homogenized in $1 \mathrm{ml}$ of $1 \mathrm{xPBS}$ and stored overnight at $-20^{\circ} \mathrm{C}$. After 
Table I. Primer sequences for reverse transcription-quantitative polymerase chain reaction.

\begin{tabular}{ll}
\hline Gene & \multicolumn{1}{c}{ Primer sequence $\left(5^{\prime} \rightarrow 3^{\prime}\right)$} \\
\hline PLA2 & F-CATGAAGGTCCTCCTGTTGCT \\
& R-AGCAACTGGGCGTCTTCCC \\
TNF- $\alpha$ & F-CGGTGCCTATGTCTCAGCCTCTTCTC \\
& R-TGGTGGTTTGGAGTGTGAGGGTCTG \\
IL-6 & F-TGGAGTCACAGAAGGAGTGGCTAAGG \\
& R-GCATAACGCACTAGGTTTGCGAGTA \\
$\beta$-actin & F-GAAGATCAAGATCATTGCTCCT \\
& R-TACTCCTGCTTGCTGATCCA
\end{tabular}

F, forward; R, reverse.

two freeze-thaw cycles at $-20^{\circ} \mathrm{C}$ overnight were performed to break cell membranes, homogenates were centrifuged at $4^{\circ} \mathrm{C}$ for $5 \mathrm{~min}$ at $5,000 \mathrm{x} \mathrm{g}$. The supernatant was removed and assayed immediately. sPLA2 (cat. no. CSB-E13206r; Cusabio Technology LLC) activity, TNF- $\alpha$ content (cat. no. PT516; Beyotime Institute of Biotechnology) and IL-6 content (cat. no. PI328; Beyotime Institute of Biotechnology) was detected via the colorimetry method using a microplate reader (Thermo Fisher Scientific, Inc.) at $450 \mathrm{~nm}$, according to kit instructions.

Western blotting. Protein samples were prepared from NP tissues using radioimmunoprecipitation assay lysis buffer (Wuhan Boster Biological Technology, Ltd.). Protein concentration was measured using a bicinchoninic acid Protein assay kit (Wuhan Boster Biological Technology, Ltd.). Protein samples $(20 \mu \mathrm{g})$ were then separated using 10\% SDS-PAGE gel and transferred onto a polyvinylidene difluoride membrane (EMD Millipore). The membrane was subsequently blocked with 5\% skimmed milk powder for $1 \mathrm{~h}$ at room temperature and incubated with primary anti-nuclear factor (NF)- $\mathrm{\kappa Bp} 65$ (cat. no. 8242) and $\beta$-actin (cat. no. 4970) antibodies (Cell Signaling Technology, Inc.) at a dilution of 1:1,000 overnight at $4^{\circ} \mathrm{C}$. Samples were then incubated with horseradish peroxidase-conjugated goat anti-rabbit immunoglobulin $\mathrm{G}$ secondary antibodies (cat. no. 7074; 1:5,000; Cell Signaling Technology, Inc.) for $1 \mathrm{~h}$ at room temperature. Protein bands were visualized using an ECL chemiluminescence kit (EMD Millipore). Protein levels were calculated relative to $\beta$-actin and Image-ProPlus software (version 6.0; Media Cybernetics, Inc.) was used for densitometry analysis.

Statistical analysis. SPSS 20.0 software (IBM Corp., Armonk, NY, USA) was used for the statistical analysis. Quantitative data are presented as the mean \pm standard deviation. One-way analysis of variance and Dunnett's test were used to determine significance among groups, and $\mathrm{P}<0.05$ was considered to indicate a statistically significant difference.

\section{Results}

Hind paw withdrawal threshold is increased following swimming in LDH rats. Prior to surgery, the hind paw withdrawal

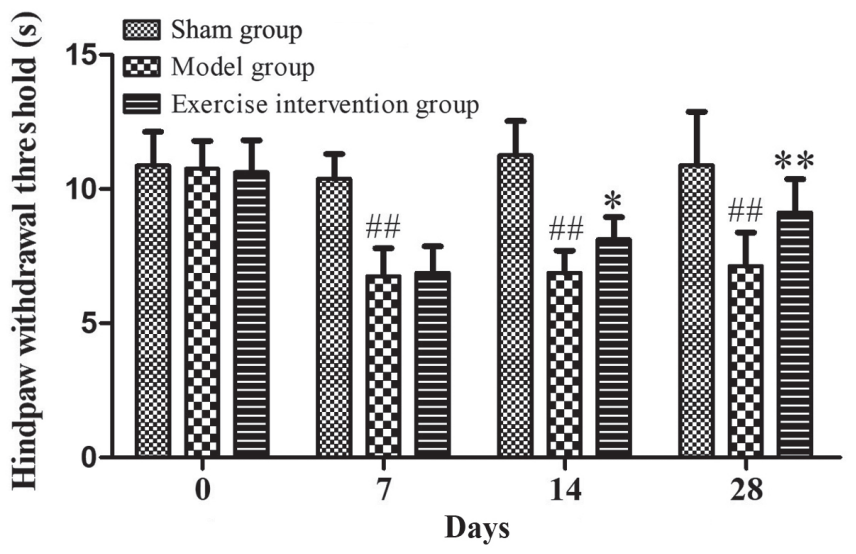

Figure 1. Swimming could increase the hind paw withdrawal threshold in lumbar disc herniation rats. ${ }^{*} \mathrm{P}<0.05$ and ${ }^{* *} \mathrm{P}<0.01$ vs. model group; ${ }^{\# \#} \mathrm{P}<0.01$ vs. sham operation group $(n=6)$.

threshold was $\sim 10 \mathrm{sec}$ in all three groups. Compared with the model group, the hind paw withdrawal threshold was significantly increased in the exercise intervention group on days 14 and 28 following surgery. As compared with the sham operation group, the hind paw withdrawal threshold of the model group was significantly reduced (Fig. 1). These data indicated that swimming could alleviate nerve root pain in $\mathrm{LDH}$ rats as the training time increased.

sPLA2 expression and IL- 6 and TNF- $\alpha$ content decreased in LDH rats following swimming. The sPLA2 expression in the exercise intervention group was decreased on day 14 , as compared with that in the model group. sPLA2 expression in the model group was significantly increased on days 7 and 14, as compared with that in the sham group (Fig. 2A). As compared with the model group, the IL- 6 and TNF- $\alpha$ content was reduced on days 14 and 28 following surgery. As compared with the sham group, the IL- 6 and TNF- $\alpha$ content clearly increased on days 7, 14 and 28 in the model group (Fig. 2B and C).

PLA2, IL- 6 and TNF- $\alpha$ mRNA expression decreases in $L D H$ rats following swimming. The mRNA expression level of PLA2 in the exercise intervention group significantly decreased on days 14 and 28 following surgery, when compared with the sham group, and the same expression in the model group was higher than that in the sham group from day 7 following surgery (Fig. 3A). The mRNA expression level of IL-6 in the exercise intervention group was significantly decreased on days 14 and 28, when compared with that in the model group, and that of the model group was increased from day 7 following surgery, when compared with that in the sham group (Fig. 3B). The mRNA expression level of TNF- $\alpha$ in the exercise intervention group was significantly lower than that in the model group on day 14 , while that in the model group was clearly increased from day 7 following surgery, compared with the sham group (Fig. 3C).

Swimming inhibits cell apoptosis in LDH rats. Apoptotic cells were detected by TUNEL and Annexin V/PI. The TUNEL staining results demonstrated that TUNEL-positive cells 

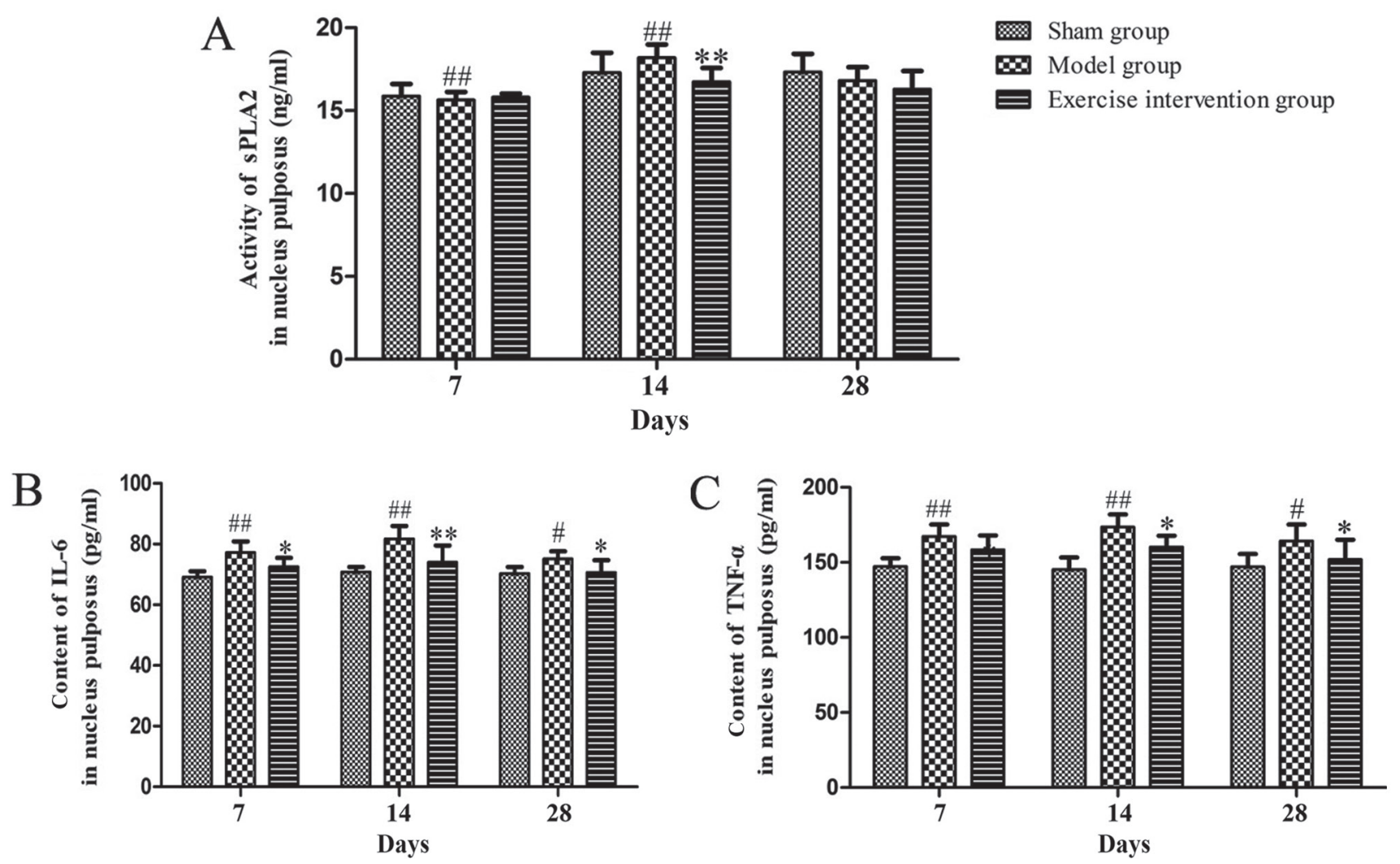

Figure 2. sPLA2 expression and IL-6 and TNF- $\alpha$ content decreased in lumbar disc herniation rats following swimming. (A) sPLA2 expression, and (B) IL-6 and (C) TNF- $\alpha$ content. ${ }^{*} \mathrm{P}<0.05$ and ${ }^{* *} \mathrm{P}<0.01$ vs. model group; ${ }^{*} \mathrm{P}<0.05$ and ${ }^{\# \#} \mathrm{P}<0.01$ vs. sham operation group $(\mathrm{n}=6)$. sPLA2, secretory phospholipase $\mathrm{A} 2 ; \mathrm{IL}$, interleukin; $\mathrm{TNF}$, tumor necrosis factor.
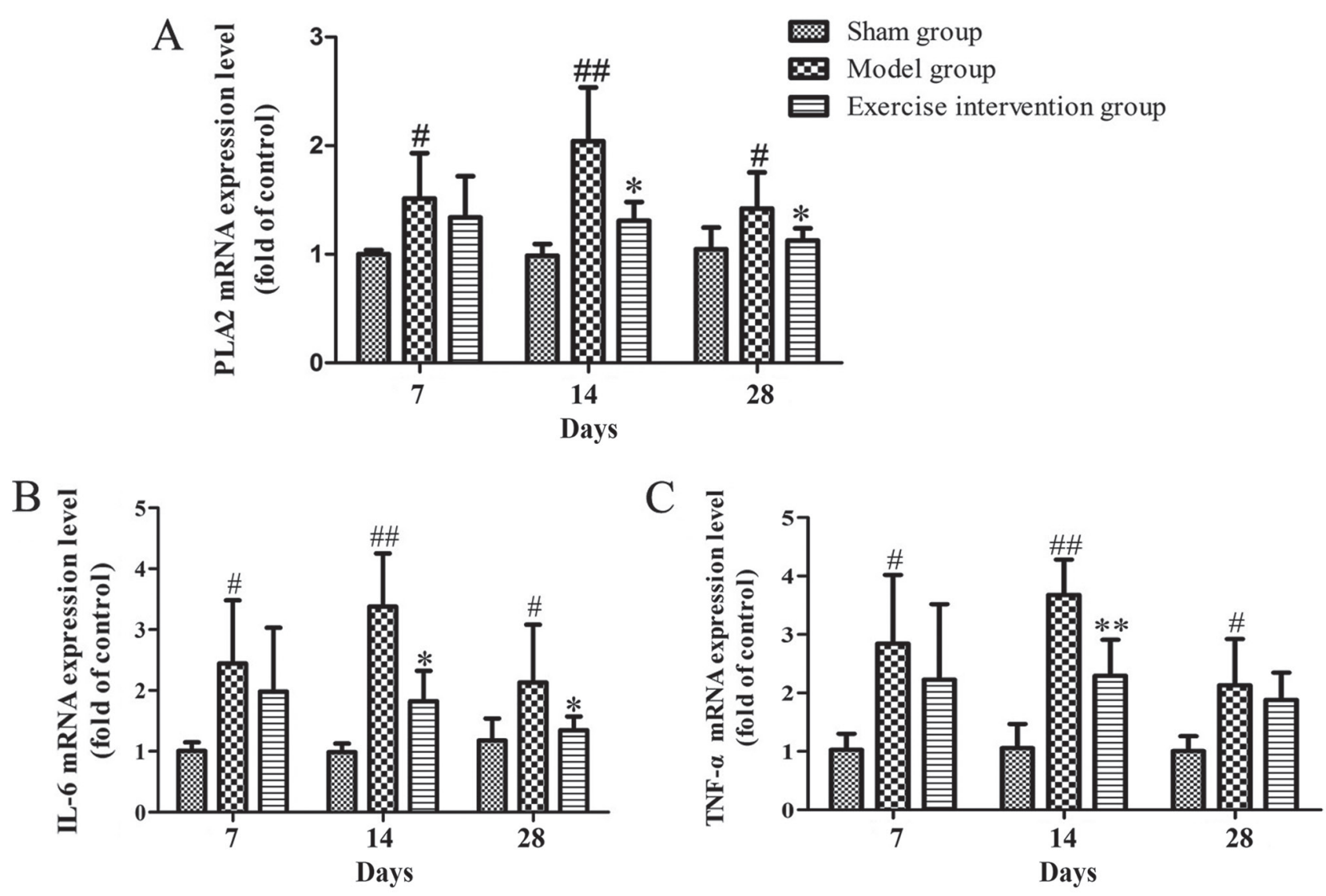

Figure 3. The PLA2, IL-6 and TNF- $\alpha$ mRNA expression decreased in lumbar disc herniation rats following swimming. (A) PLA2, (B) IL-6 and (C) TNF- $\alpha$ mRNA expression. ${ }^{*} \mathrm{P}<0.05$ and ${ }^{* *} \mathrm{P}<0.01$ vs. model group; ${ }^{\#} \mathrm{P}<0.05$ and ${ }^{\# /} \mathrm{P}<0.01$ vs. sham operation group ( $\mathrm{n}=6$ ). sPLA2, secretory phospholipase A2; IL, interleukin; TNF, tumor necrosis factor. 


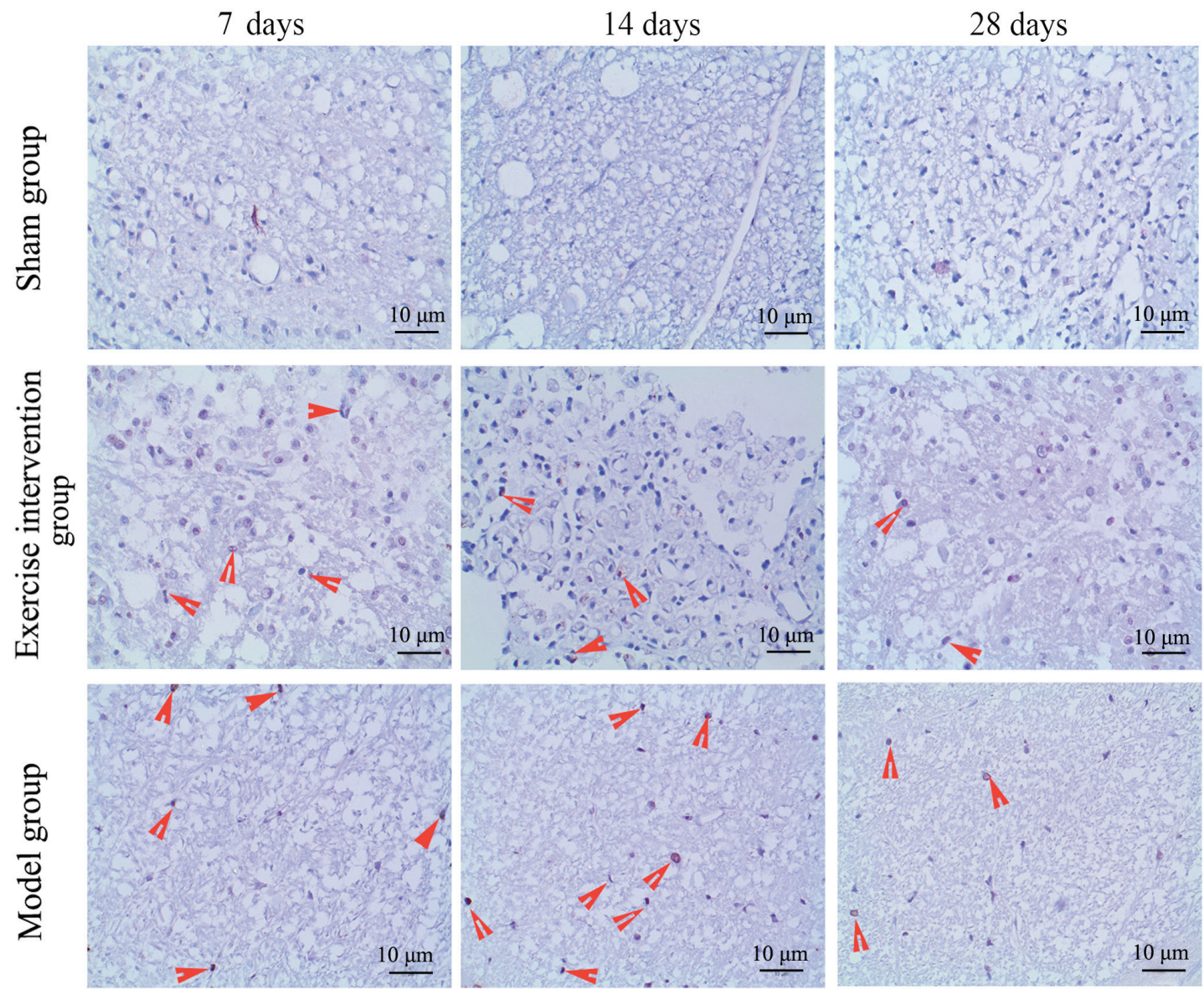

Figure 4. Terminal deoxynucleotidyl-transferase-mediated dUTP nick end labeling-positive cells decreased in lumbar disc herniation rats following swimming. Red arrows indicate apoptotic cells

were observed in the model and exercise intervention groups, but those in the exercise intervention group were markedly decreased, as compared to those in the model group (Fig. 4). The flow cytometry results demonstrated that the apoptotic rate in the exercise intervention group was significantly decreased from day 7 following surgery, as compared with that in the model group. The rate in the model group was significantly increased from day 7 following surgery, as compared with that in the sham group (Fig. 5).

Swimming inhibits the activation of $N F-\kappa B p 65$ in LDH rats. Western blotting results demonstrated that the NF- $\kappa \mathrm{Bp} 65$ protein expression level in the model group was significantly increased, when compared with that in the sham group on days 7, 14 and 28 following surgery, and was significantly higher on day 14, as compared with day 7 . In the exercise intervention group, the $\mathrm{NF}-\kappa \mathrm{Bp} 65$ protein expression was significantly decreased, as compared with that in model group, and was significantly lower on day 28 , as compared to day 7 (Fig. 6).

\section{Discussion}

Modern medical studies have demonstrated that LDH-induced nerve root pain is mainly caused by mechanical compression, autoimmunity and chemical stimulation of inflammatory factors $(7,20)$. Among them, mechanical oppression is the main pathogenic factor. Early modern medicine's understanding of LDH mainly focused on mechanical oppression, which was considered the only pain-causing factor (21). With the progress and development of modern medicine, the theory of molecular biology was introduced in LDH. A previous study demonstrated that the inflammatory factors in the body fluids and tissues of the lumbar process have toxic effects on the nervous system, and can stimulate nerves and produce the feeling of pain, causing nerve root pain in LDH (22). This finding demonstrated that mechanical compression was not the only cause of lumbar and leg pain in $\mathrm{LDH}$, and that relief from compression injury was no longer the only treatment.

The generation and maintenance of chronic neuropathic pain is the common result of many inflammatory factors. PLA2 is a key enzyme that produces other inflammatory substances, which can hydrolyze glycosphospholipids specifically, and produce free fatty acids and hemolytic phospholipids, mainly arachidonic acid (23), causing inflammation in the lumbar region and stimulating local sensors that ultimately cause pain. TNF- $\alpha$ is released by macrophages and is a cytokine with a strong pain-causing effect, it can cause root pain while continuing to damage cells, promoting the production of other inflammatory factors, such as cyclooxygenase 2, IL-6 and IL-1 (24). TNF- $\alpha$ can gather and regulate neutrophil and eosinophilic cells directly, disrupt the metabolism and cellular 

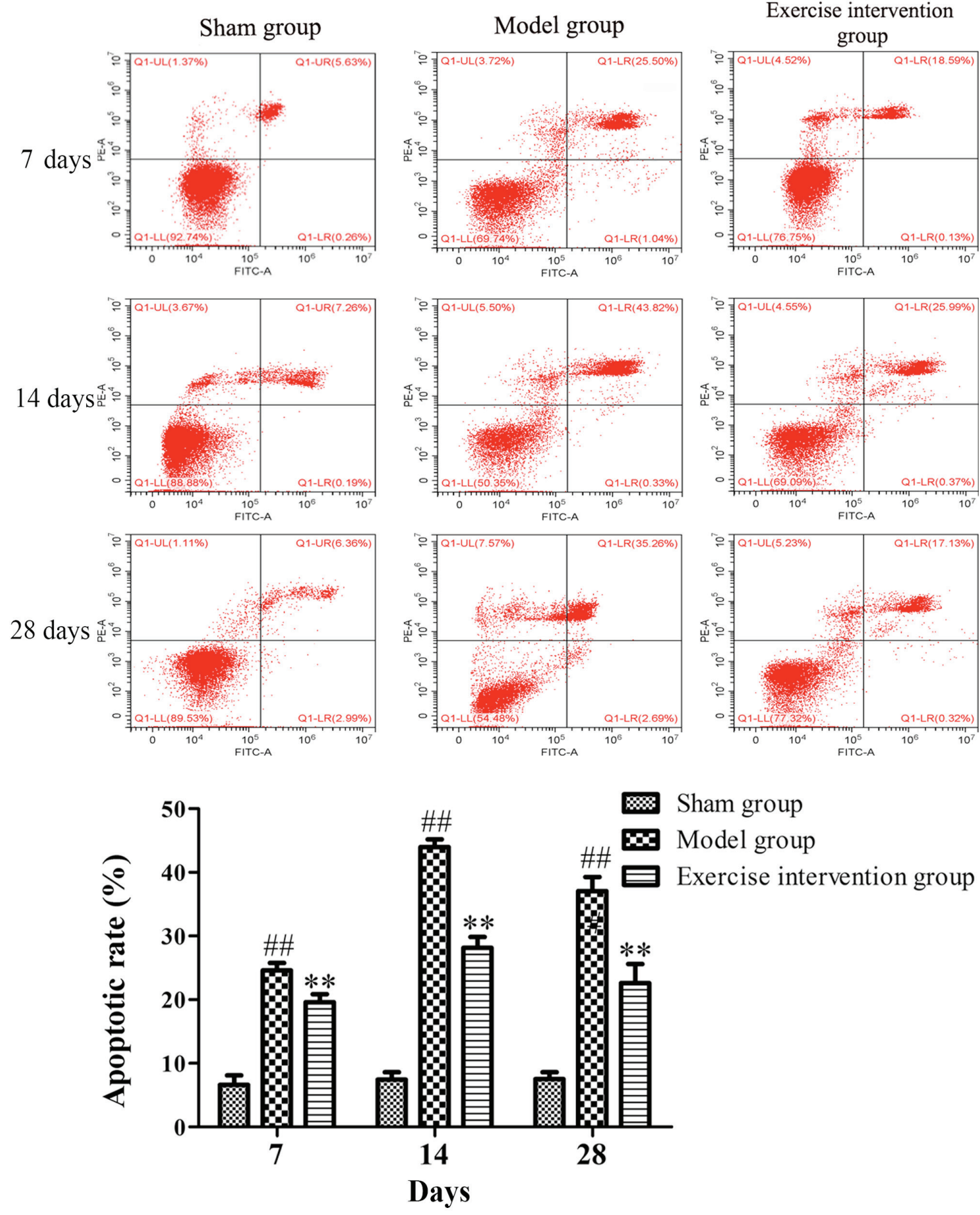

Figure 5. Cell apoptosis decreased in lumbar disc herniation rats following swimming. Annexin-V/propidium iodide double-staining and flow cytometry was applied to detect the apoptotic cells. ${ }^{* *} \mathrm{P}<0.01$ vs. model group; ${ }^{\# \#} \mathrm{P}<0.01$ vs. sham group $(\mathrm{n}=6)$. FITC, fluorescein isothiocyanate.

immune response, and affect the normal process of cell division and differentiation, and produce cytotoxicity and neurotoxicity $(25,26)$. IL-6 is mainly secreted by monocytes/macrophages, as well as B and $\mathrm{T}$ lymphocytes, it is an acute reactive protein and can induce acute inflammatory reaction, promoting and regulating the inflammatory response in different types of cell division and differentiation (27). The present study demonstrated that the sPLA2 expression, TNF- $\alpha$ and IL- 6 content, and the PLA2, TNF- $\alpha$ and IL- 6 mRNA expression levels in the exercise intervention group decreased significantly, as compared with those in the model group, which was consistent with the trend of hind paw withdrawal threshold in rats. These results indicated that the increased PLA2, TNF- $\alpha$, and IL-6 activity in the NP has an important role in neuropathic pain of LDH, also suggested that swimming can inhibit inflammatory reaction and improve the nerve root pain of $\mathrm{LDH}$ rats.

A number of studies have indicated that apoptosis is involved in intervertebral disc tissue degeneration of 

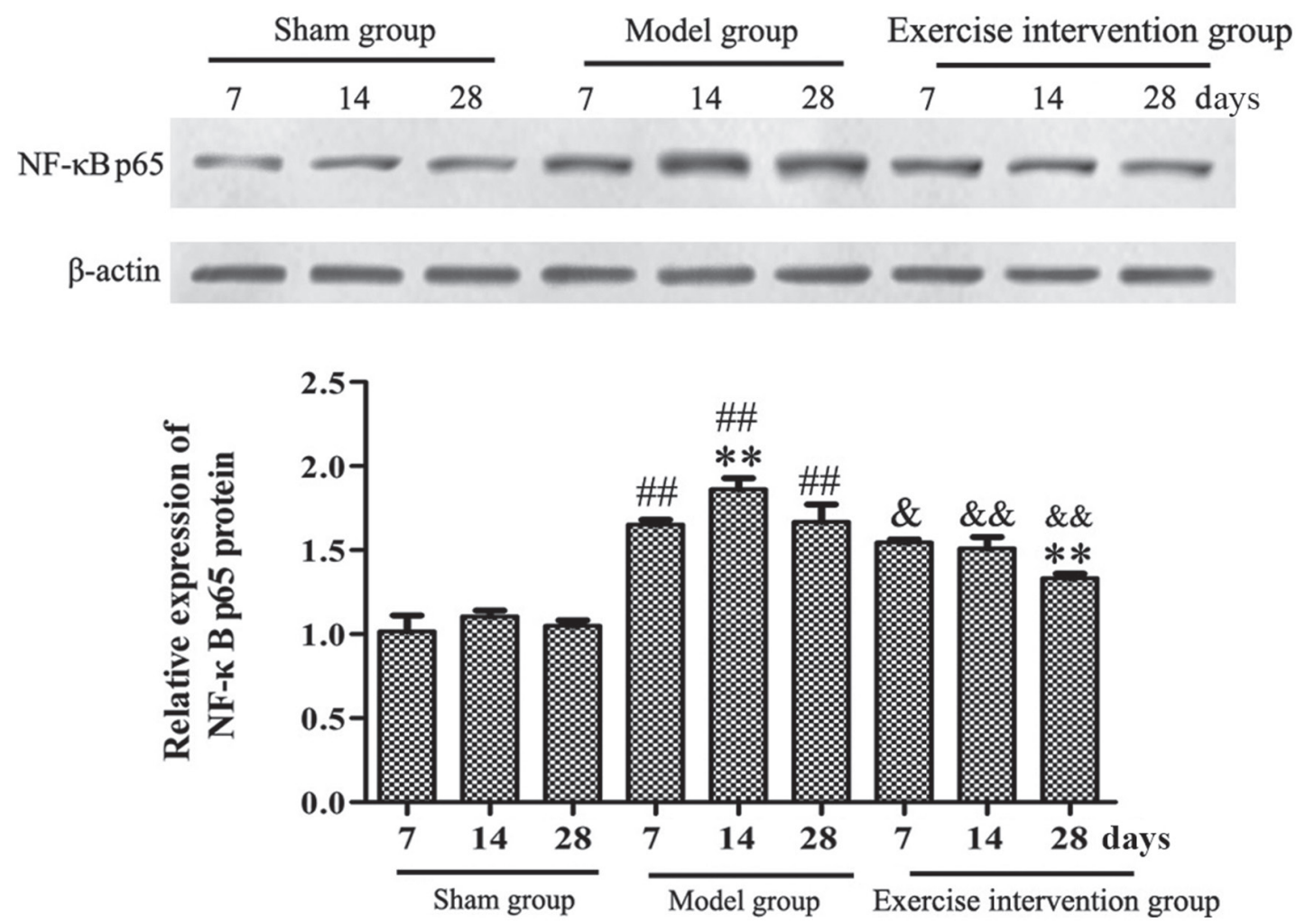

Figure 6. Swimming inhibited the activation of NF-kBp65 in lumbar disc herniation rats. Western blotting was performed to detect the expression of the

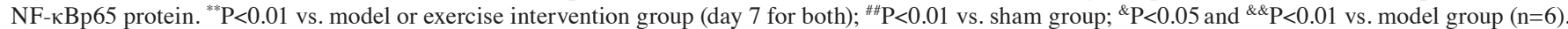
$\mathrm{NF}$, nuclear factor.

pathophysiological changes (28,29). Excessive cell apoptosis results in a reduction in the activity of intervertebral disc cells and a subsequent decrease in extracellular matrix change in synthesis and composition, contributing to the pathology of intervertebral disc degeneration (30). In the present study, it was observed that swimming markedly reduced the number of apoptotic cells in NP of LDH rats. And the apoptosis trend was consistent with the change of inflammatory factors. Wang et al (31) previously reported that the IL-1, IL-4, and TNF- $\alpha$ expression levels contribute to the apoptosis of disc cells. Therefore, it was hypothesized that excessive activation of inflammatory factors may promote apoptosis in LDH rats.

$\mathrm{NF}-\kappa \mathrm{Bp} 65$ is the main effect factor of $\mathrm{NF}-\kappa \mathrm{B}$, which can promote the release of various inflammatory factors by activating the downstream inflammatory signal, and increase the chronic inflammatory injury of intestinal mucosa tissues (32). The activation of NF- $\kappa \mathrm{Bp} 65$ promoted inflammation and hyperalgesia in rat adjuvant-induced arthritis (33). The present findings demonstrated that the $\mathrm{NF}-\kappa \mathrm{Bp} 65$ protein expression level was significantly decreased following swimming, which indicated that the reduction of neuronal pain and inflammation in LDH rats by swimming may be associated with the inhibition of NF- $\kappa$ Bp65 activity.

In conclusion, the present findings indicate that swimming can effectively reduce the nerve root pain in LDH rats, which may be associated with the downregulation of inflammatory factors, inhibition of the activity of NF- $\mathrm{Np} 65$ pathway in NP, and inhibition of apoptosis of NP cells. These findings are encouraging and suggest that swimming might be employed as a novel and effective therapy for LDH patients in the future.

\section{Acknowledgements}

Not applicable.

\section{Funding}

The present study was supported by a grant from the Sichuan Health and Family Planning Commission Research Project (grant no. 130198).

\section{Availability of data and materials}

The datasets used and/or analyzed during the current study are available from the corresponding author on reasonable request.

\section{Authors' contributions}

YH, ZZ and DY conceived and designed the experiments. YH, ZZ, DY, LH, FH and DL performed the experiments. LY, RW, LZ, XH and JH analyzed the data and provided assistance with the experiments. YH and ZZ wrote the manuscript. All authors have read and approved the final version of this manuscript.

\section{Ethics approval and consent to participate}

The experimental protocol for the care and use of laboratory animals was approved by the Experimental Animal Ethics Committee of West China Hospital of Sichuan University (Chengdu, China). 


\section{Patient consent for publication}

Not applicable.

\section{Competing interests}

The authors declare that they have no competing interests.

\section{References}

1. Krekoukias G, Gelalis ID, Xenakis T, Gioftsos G, Dimitriadis Z and Sakellari V: Spinal mobilization vs conventional physiotherapy in the management of chronic low back pain due to spinal disk degeneration: A randomized controlled trial. J Man Manip Ther 25: 66-73, 2017.

2. Haines SJ, Jordan N, Boen JR, Nyman JA, Oldridge NB and Lindgren BR; LAPDOG/LEAPDOG Investigators: Discectomy strategies for lumbar disc herniation: Results of the LAPDOG trial. J Clin Neurosci 9: 411-417, 2002.

3. Ahn SH, Cho YW, Ahn MW, Jang SH, Sohn YK and Kim HS: mRNA expression of cytokines and chemokines in herniated lumbar intervertebral discs. Spine (Phila Pa 1976) 27: 911-917, 2002

4. Orief T, Orz Y, Attia W and Almusrea K: Spontaneous resorption of sequestrated intervertebral disc herniation. World Neurosurg 77: 146-152, 2012.

5. Karademir M, Eser O and Karavelioglu E: Adolescent lumbar disc herniation: Impact, diagnosis, and treatment. J Back Musculoskelet Rehabil 30: 347-352, 2017.

6. Karaaslan B, Aslan A, Borcek AO and Kaymaz M: Clinical and surgical outcomes of upper lumbar disc herniations: A retrospective study. Turk J Med Sci 47: 1157-1160, 2017.

7. Cho HK, Kim SY, Choi MJ, Baek SO, Kwak SG and Ahn SH: The effect of GCSB-5 a new herbal medicine on changes in pain behavior and neuroglial activation in a rat model of lumbar disc herniation. J Korean Neurosurg Soc 59: 98-105, 2016.

8. Schroeder GD, Guyre CA and Vaccaro AR: The epidemiology and pathophysiology of lumbar disc herniations. Seminars Spine Surg 28: 2-7, 2016

9. Gugliotta M, da Costa BR, Dabis E, Theiler R, Jüni P, Reichenbach S, Landolt H and Hasler P: Surgical versus conservative treatment for lumbar disc herniation: A prospective cohort study. BMJ Open 6: e012938, 2016.

10. Pearson AM, Blood EA, Frymoyer JW, Herkowitz H, Abdu WA Woodward R, Longley M, Emery SE, Lurie JD, Tosteson TD and Weinstein JN: SPORT lumbar intervertebral disk herniation and back pain. Spine (Phila Pa 1976) 33: 428-435, 2008.

11. Shepard N and Cho W: Recurrent lumbar disc herniation: A review. Global Spine J 9: 202-209, 2019.

12. Righesso O, Falavigna A and Avanzi O: Correlation between persistent neurological impairment and clinical outcome after microdiscectomy for treatment of lumbar disc herniation. Neurosurgery 70: 396-397, 2012

13. Brotz D, Kuker W, Maschke E, Wick W, Dichgans J and Weller M: A prospective trial of mechanical physiotherapy for lumbar disk prolapse. J Neurol 250: 746-749, 2003.

14. Pourahmadi MR, Taghipour M, Ebrahimi Takamjani I, Sanjari MA, Mohseni-Bandpei MA and Keshtkar AA: Motor control exercise for symptomatic lumbar disc herniation: Protocol for a systematic review and meta-analysis. BMJ Open 6: e012426, 2016

15. Yan J, Hu S, Zou K, Xu M, Wang Q, Miao X, Yu SP and Xu GY: Inhibition of cystathionine $\beta$-synthetase suppresses sodium channel activities of dorsal root ganglion neurons of rats with lumbar disc herniation. Sci Rep 6: 38188, 2016.

16. Zhu X, Cao S, Zhu MD, Liu JQ, Chen JJ and Gao YJ: Contribution of chemokine CCL2/CCR2 signaling in the dorsal root ganglion and spinal cord to the maintenance of neuropathic pain in a rat model of lumbar disc herniation. J Pain 15: 516-526, 2014
17. Zhao LR, Xing RL, Zhang L, Xu B, Li XC and Wang PM: Transient receptor potential signaling pathways influence the hyperalgesia in a rat model of mechanical lumbar disc herniation. Myopain 23: 118-124, 2017.

18. Kameda T,Kaneuchi Y, Sekiguchi M and Konno SI: Measurement of mechanical withdrawal thresholds and gait analysis using the CatWalk method in a nucleus pulposus-applied rodent model. J Exp Orthop 4: 31, 2017.

19. Livak KJ and Schmittgen TD: Analysis of relative gene expression data using real-time quantitative PCR and the 2(-Delta Delta C(T) ) method. Methods 25: 402-408, 2001

20. de Souza Grava AL, Ferrari LF and Defino HL: Cytokine inhibition and time-related influence of inflammatory stimuli on the hyperalgesia induced by the nucleus pulposus. Eur Spine J 21: 537-545, 2012.

21. diZerega GS, Traylor MM, Alphonso LS and Falcone SJ: Use of temporary implantable biomaterials to reduce leg pain and back pain in patients with sciatica and lumbar disc herniation. Materials (Basel) 3: 3331-3368, 2010.

22. Yan J, Zou K, Liu X, Hu S, Wang Q, Miao X, Zhu HY, Zhou Y and Xu GY: Hyperexcitability and sensitization of sodium channels of dorsal root ganglion neurons in a rat model of lumber disc herniation. Eur Spine J 25: 177-185, 2016.

23. Russell RL, Levine JM, Jeffery ND, Young C, Mondragon A, Lee B, Boudreau CE, Welsh CJ and Levine GJ: Arachidonic acid pathway alterations in cerebrospinal fluid of dogs with naturally occurring spinal cord injury. BMC Neurosci 17: 31, 2016.

24. Gui HQ,Zhi-Sheng MO and Yang J: Value of TNF- $\alpha$ inhibitor in the treatment of lumbar disc herniation. Med Innovation China, 2017.

25. Shang QS, Huang B and Sheng WH: Detection of tumor necrosis factor- $\alpha$ and interleukin-18 in herniated intervertebral disc and their significance. Orthopedic J China 17: 385-387, 2009.

26. Barichello T, dos Santos ID, Savi GD, Florentino AF, Silvestre C, Comim CM, Feier G, Sachs D, Teixeira MM, Teixeira AL and Quevedo J: Tumor necrosis factor alpha (TNF- $\alpha$ lpha) levels in the brain and cerebrospinal fluid after meningitis induced by Streptococcus pneumoniae. Neurosci Lett 467: 217-219, 2009.

27. Hunter CA and Jones SA: IL-6 as a keystone cytokine in health and disease. Nat Immunol 16: 448-457, 2015.

28. Alini M, Eisenstein SM, Ito K, Little C, Kettler AA, Masuda K, Melrose J, Ralphs J, Stokes I and Wilke HJ: Are animal models useful for studying human disc disorders/degeneration? Eur Spine J 17: 2-19, 2008.

29. Chen J, Hou C, Chen X, Wang D, Yang P, He X, Zhou J and Li H: Protective effect of cannabidiol on hydrogen peroxide-induced apoptosis, inflammation and oxidative stress in nucleus pulposus cells. Mol Med Rep 14: 2321-2327, 2016.

30. Kermani HR, Hoboubati H, Esmaeili-Mahani $S$ and Asadi-Shekaari M: Induction of intervertebral disc cell apoptosis and degeneration by chronic unpredictable stress. J Neurosurg Spine 20: 578-584, 2014.

31. Wang SL, Yu YL, Tang CL and Lv FZ: Effects of TGF- $\beta 1$ and IL-1 $\beta$ on expression of ADAMTS enzymes and TIMP-3 in human intervertebral disc degeneration. Exp Ther Med 6: 1522-1526, 2013.

32. Gan H, Ouyang Q, Chen Y and Xia Q: Activation of nuclear factor-kappaB and effects of anti-inflammatory treatment thereon in intestinal mucosa of patients with ulcerative colitis. Zhonghua Yi Xue Za Zhi 82: 384-388, 2002 (In Chinese).

33. Luo JG, Zhao XL, Xu WC, Zhao XJ, Wang JN, Lin XW, Sun T and Fu ZJ: Activation of spinal NF- $\kappa \mathrm{B} / \mathrm{p} 65$ contributes to peripheral inflammation and hyperalgesia in rat adjuvant-induced arthritis. Arthritis Rheumatol 66: 896-906, 2014.

This work is licensed under a Creative Commons Attribution-NonCommercial-NoDerivatives 4.0 International (CC BY-NC-ND 4.0) License. 